\title{
RBSM-Based Analysis of Crack Control Effectiveness of Polymer Concrete Overlay for Reinforced Concrete Structures
}

\author{
Yuliia KHMUROVSKA*, Petr ŠTEMBERK** \\ *Czech Technical University, Thákurova 7, 16629 Prague 6, Czech Republic, E-mail: yuliia.khmurovska@fsv.cvut.cz. \\ **Czech Technical University, Thákurova 7, 16629 Prague 6, Czech Republic, E-mail: stemberk@fsv.cvut.cz. \\ cross $^{\text {ref }}$ http://dx.doi.org/10.5755/j01.mech.23.6.18931
}

\section{Introduction}

Delamination and spalling of the concrete cover due to degradation of concrete or corrosion of steel reinforcement (Fig. 1) are the most common reasons why concrete structures need to be repaired. Either of the concrete degradation or the steel reinforcement corrosion are triggered by ingress of chemically aggressive substances which enter the concrete microstructure thru cracks. Therefore, the crack width is of importance when durability of concrete structures is considered.

Routinely, the crack width is controlled by arrangement of the ordinary reinforcing steel bars, when, however, the crack initiation cannot have avoided and already the crack width is targeted by prescription of the amount of reinforcement and spacing between the steel bars. This said, it is obvious that the cracks do occur and thus the resistance of concrete structures against ingress of aggressive chemicals is compromised.

One of the modern techniques for repairing concrete structures is installation of an overlay over the affected surface of a concrete structure. The overlay is made of a material which helps to disperse the major macrocrack in to multiple microcracks (Fig. 2) which prohibit the ingress of the vulnerable substances into the concrete mass. The material used for the overlay is often referred to as the Engineered Cementitious Composite (ECC) and it also includes polyvinyl alcohol fibers (PVA) which help to modify the post-peak behavior if the concrete overlay, as can be seen in Fig. 2. The tensile ductility in the form of pseudo strain hardening is achieved by the multiple cracking of the cement matrix. The research of the tensile behavior of PVA-ECC has shown the formation of a large number of tiny cracks with a width of less than $60 \mu \mathrm{m},[1,2]$. The presence of microcracks provides high durability of this material because the transport of environmental products into the concrete takes place through the cracks with a width above $0.1 \mathrm{~mm} \mathrm{[3].}$

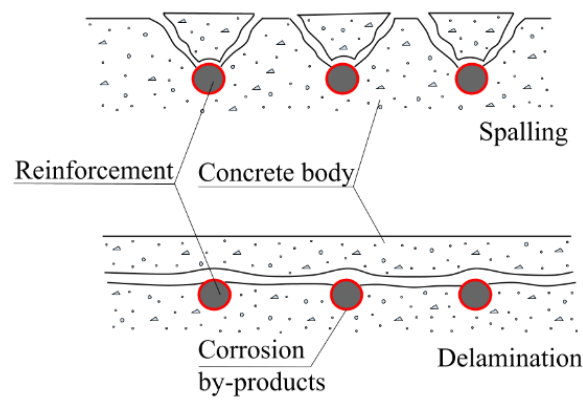

Fig. 1 Damage of concrete cover (two types)

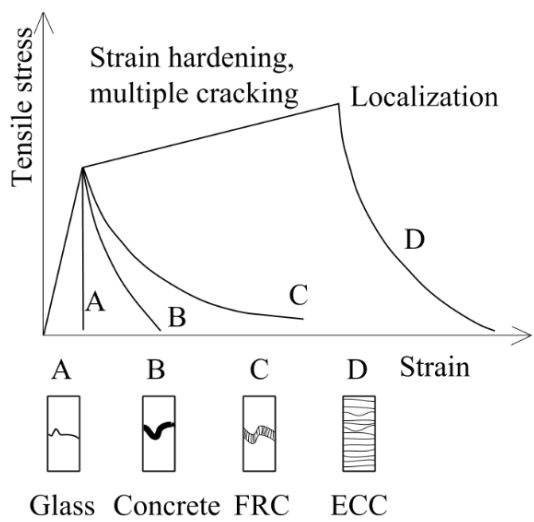

Fig. 2 Tensile stress-stain behavior of (A) brittle, (B) quasi-brittle, (C) strain softening, (D) strain hardening materials $[4,5]$

Besides the enhanced ductility, the adhesion properties of the repair material play the crucial role in concrete cover repair. The new layer should provide reasonably high bonding performance with the old concrete substrate and the reinforcing steel bars so that the full interaction between the two materials is ensured. According to available research [6], PVA-ECC allows for much stronger bond compared to ordinary mortar, which makes PVA-ECC suitable for the described purposes. Thus, this study deals with concrete to PVA-ECC bond only.

The numerical simulation of the structural response of a reinforced concrete with a PVA-ECC overlay shown in this paper utilizes the Rigid-Body-Spring Model (RBSM) method which is suitable for both the static and dynamic analyses. This method was selected as it helps to analyze the crack patterns and the crack widths. This method also allows to investigate the possible delamination effect which may occur in the reinforced concrete structural detail considered in this paper.

\section{RBSM modelling}

The Rigid-Body-Spring Model (RBSM) is a type of a discrete method model which was invented by Kawai, [7]. The main benefit of the RBSM is the ability to model difficult three-dimensional behavior of a material, such as concrete, by using a relatively simple constitute model that can be validated easily by classical benchmark tests. The random geometry of the particles, which is mostly provided by Voronoi tessellation, [8], helps to simulate crack patterns and their propagation. The material is modeled as a set of undeformable rigid-bodies interconnected by sets of springs on their surfaces. The Voronoi cell shape rigid particles are generated to reduce mesh bias on the crack 
initiation and propagation, which is ensured by the random geometry.

In the model used in the presented analysis, each rigid-body has six degrees of freedom (three translational and three rotational) defined at the nuclei of the Voronoi cells. The center of gravity and the vertices of the boundary surface created by two neighboring particles is split into triangles, as shown in Fig. 3. Then, one normal and two shear springs are defined at the center of gravity of these triangles in order to account for the effect of bending and torsion without the use of rotational springs, [9], which reduced the number of material parameters.

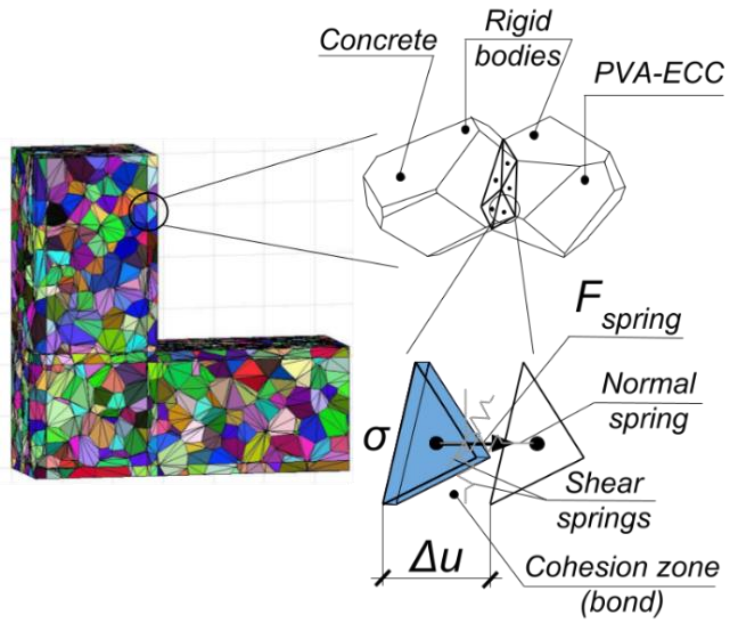

Fig. 3 Rigid-Body-Spring Model (RBSM)

\section{Description of concrete substrate}

The material model within the 3D RBSM for the concrete substrate (original concrete part of the structure) in tension, compression and shear is defined in figure 4 for easy understanding. It should be noted that all material parameters used later in the analyses are provided here.

The tensile stress-strain relation for the normal springs is linear elastic with the slope corresponding to an elastic modulus, $E$, up to tensile-strength dependent value $\sigma_{t}$ with the bilinear softening behavior after cracking as shown in Fig. 4, a), [9-11]. In Fig. 4, a), $f_{t}$ is the tensile strength, $E_{\text {exp }}$, is the experimentally obtained elastic modulus, $G_{f}$ is the fracture energy and $h$ is the distance between the nuclei of the neighboring rigid-bodies.

The compression model for the normal springs is modeled as a combination of two quadratic functions with the resultant S-shape curve (Fig. 4, b)). In Fig. 4, b), $f_{c}$ is the compressive strength. The compressive failure is not considered in the model since the failure is always decided by tension, or shear, [9-11]. The compression model is given by the following formulas:

$$
\begin{aligned}
& \sigma=\left\{\begin{array}{cc}
a_{0} \varepsilon^{2}+b_{0} \varepsilon & \varepsilon>\varepsilon_{c 1} \\
a_{1} \varepsilon^{2}+b_{1} \varepsilon+c_{1} & \varepsilon \leq \varepsilon_{c 1}
\end{array},\right. \\
& a_{0}=-\frac{E\left(1-\alpha_{c 1}\right)}{2 \varepsilon_{c 1}}, \\
& b_{0}=E,
\end{aligned}
$$

$$
\begin{aligned}
& a_{1}=-\frac{E\left(\alpha_{c 2}-\alpha_{c 1}\right)}{2\left(\varepsilon_{c 2}-\varepsilon_{c 1}\right)}, \\
& b_{1}=-\frac{E\left(\alpha_{c 1} \varepsilon_{c 2}-\alpha_{c 2} \varepsilon_{c 1}\right)}{\varepsilon_{c 2}-\varepsilon_{c 1}}, \\
& c_{1}=-a_{1} \varepsilon_{c 1}^{2}+b_{1} \varepsilon_{c 1}+\sigma_{c} .
\end{aligned}
$$

The shear stress-strain relation is defined as a combination of the stresses and strains of two shear springs $\left(\gamma_{l}, \gamma_{m}\right)$, where $l$ and $m$ denote two perpendicular directions. The shear stress is increasing elastically with the slope of the shear modulus, $G$, up to the shear strength, $\tau_{f}$. Then, the softening behavior is assumed (Fig. 4, c)). The slope of softening, $K$, depends on the normal spring stresses through the softening ratio, $\beta$, that is increasing up to the maximum value with increasing of the tensile stresses (Fig 4, d)). [9-11]. The shear behavior is defined by the following formulas:

$$
\begin{aligned}
& \tau=\left\{\begin{array}{cc}
G \gamma & \gamma<\gamma_{f} \\
\max \left(\tau_{f}+K\left(\gamma-\gamma_{f}\right), 0.1 \tau_{f}\right) & \gamma \geq \gamma_{f}
\end{array},\right. \\
& \beta=\min \left(\beta_{0}+\chi\left(\sigma / \sigma_{b}\right), \beta_{\max }\right),
\end{aligned}
$$

where $\sigma_{b}$ is the stress, which corresponds to the real compressive strength of concrete, as it is common in numerical analyses. In other words, $\sigma_{b}$ corresponds to the mean value of compressive strength provided by construction standards, such as [12].

The Mohr-Coulomb type criterion is assumed as the shear spring failure criteria (Fig. 4, e)), [9-11]. The decrease of the shear stress with the increase of the crack width is taken into consideration as follows, [9-11]:

$$
\begin{aligned}
& \tau=\left\{\begin{array}{cc}
\beta_{c r} G \gamma & \gamma<\gamma_{f t} \\
\beta_{c r} \max \left(\tau_{f t}+K\left(\gamma_{\max }-\gamma_{f t}\right), 0.1 \tau_{f}\right) & \gamma \geq \gamma_{f t}
\end{array},\right. \\
& \beta_{c r}=\frac{\varepsilon_{t}}{\varepsilon} \exp \left\{\frac{k}{\varepsilon_{t u}}\left(\varepsilon-\varepsilon_{t}\right)\right\}, \\
& \tau_{f t}=c-\sigma_{t} \tan \phi .
\end{aligned}
$$

\section{Description of PVA-ECC}

The material model within the 3D RBSM for the PVA-ECC in tension was taken from the experimental investigation of the PVA-ECC with 2\% fiber content, [13], and is shown in Fig. 5, a). The normal spring in tension is modeled as linear elastic up to the tensile strength $\sigma_{t}$ with a linear hardening branch after cracking and a bilinear softening behavior after crack localization. The strain characteristics of the PVA-ECC derived from the fracture energy of concrete with the assumption that PVA-ECC behavior before cracking and after crack localization is similar to concrete behavior, [13].

Since the compression behavior of the PVA-ECC 
is close to concrete (Fig. 4, b)), [13], the compression model of the PVA-ECC is assumed to be the same as in the material model for concrete and is given by Eqs. 1 thru 6 .

The shear stress-strain diagram is shown in Fig. 5, b) where the slope of softening $K$ also depends on the normal spring stresses through the softening ratio $\beta$ (Fig. 4, d) and thus is also given by Eqs. 7 thru 11 .

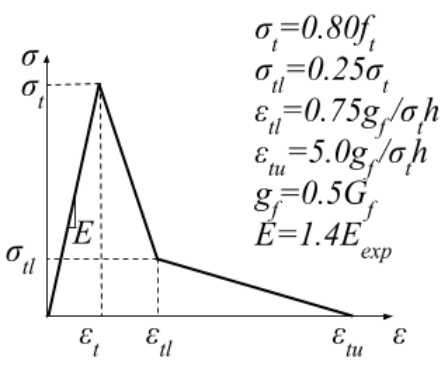

a

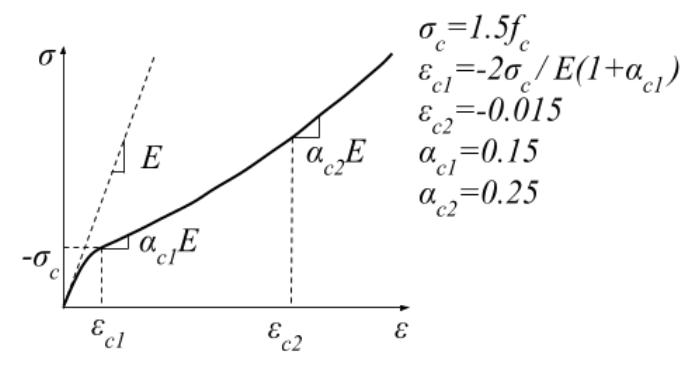

b

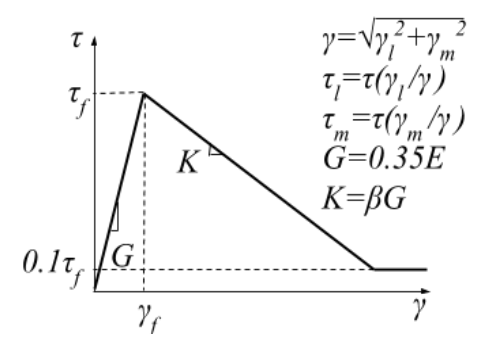

c

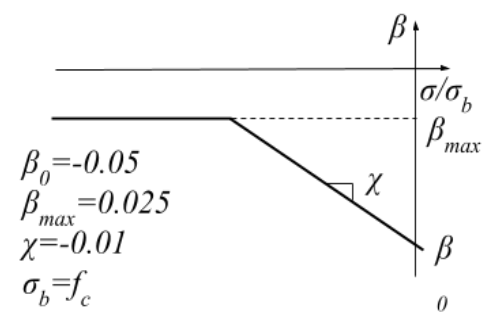

d

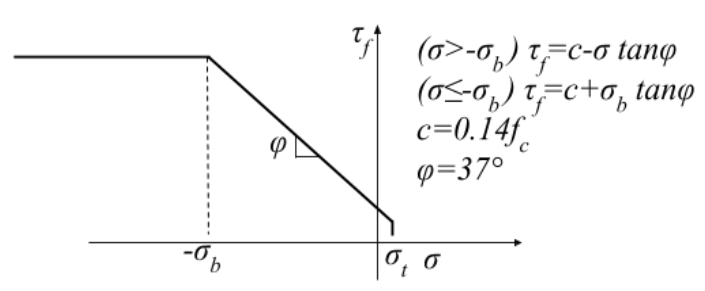

Fig. 4 Concrete material model: a) tension model of normal spring; b) compression model of normal spring; c) shear spring model; d) softening coefficient of shear spring; e) Mohr-Coulomb type criterion

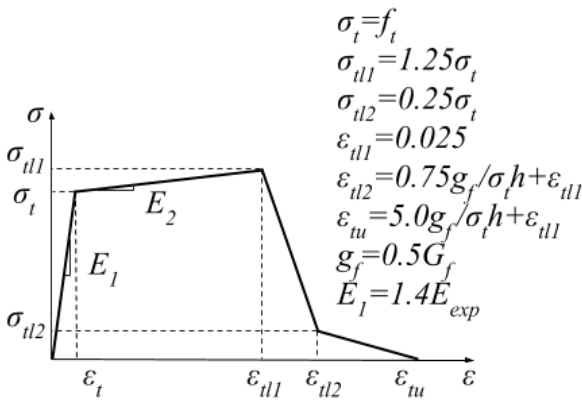

a

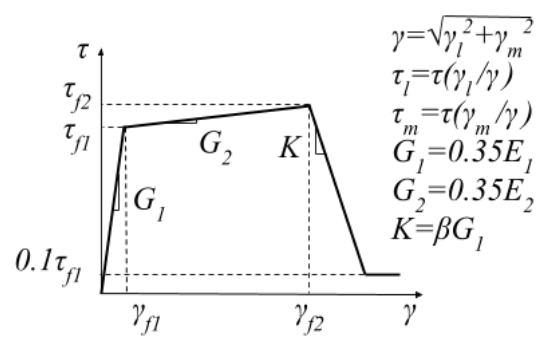

b

Fig. 5 PVA-ECC material model: a) tension model of normal spring; b) shear spring model

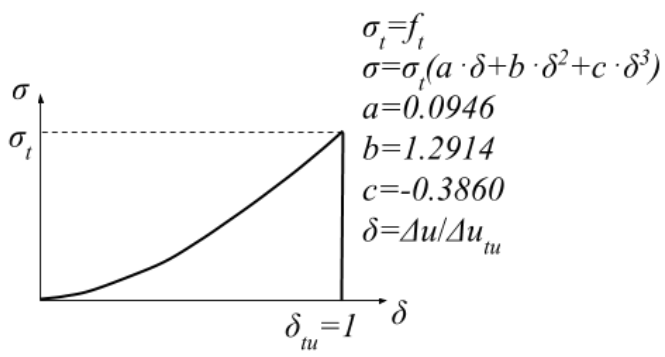

a

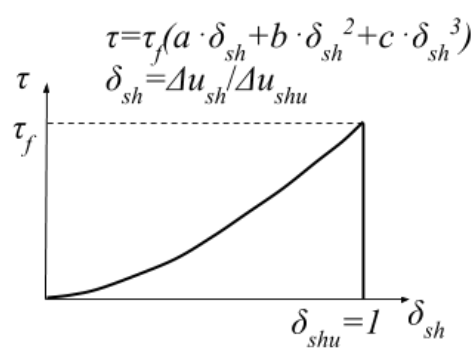

$\mathrm{b}$

Fig. 6 PVA-ECC-to-concrete bond material model: a) tension model of normal spring; b) shear spring model

The Mohr-Coulomb type failure criterion is also assumed (Fig. 4, e)), where

$$
\begin{aligned}
& \tau_{f 1}=\tau_{f} \\
& \tau_{f 2}=\left\{\begin{array}{ll}
c-0.8 \sigma \tan \phi & \sigma>-\sigma_{b} \\
c-1.25 \sigma \tan \phi & \sigma \leq-\sigma_{b}
\end{array} .\right.
\end{aligned}
$$

\section{Description of bond between two materials}

The trend of the stress-strain curve of the bond is similar to the stress-strain curve of the PVA fibers in tension, [14], which means that the bond is provided mostly by the PVA fibers. The tensile bond behavior was presented in previous numerical and experimental study in [6] 
where the stress-strain tensile relation is expressed by a cubic parabola up to the failure without any softening brunch, as shown in Fig. 6, a), where $\delta$ is the relative strain, $\delta_{u}$ is the ultimate relative strain, $\Delta u$ is the relative normal displacement of the spring, $\Delta u_{t u}$ is its ultimate relative normal displacement and $a, b$ and $c$ are shape parameters [6].

The bond compression strength is accepted as the average of the strengths of the PVA-ECC and concrete. The stress-strain relation is shown in Fig. 4, b).

The shear behavior is similar to that in tension and is shown in Fig. $6, \mathrm{~b}$ ), where $\delta_{s h}$ is the relative shear strain, $\delta_{s h u}$ is the ultimate relative strain, $\Delta u_{s h}$ is the relative shear displacement of the spring and $\Delta u_{s h u}$ is its ultimate relative shear displacement. The shear spring model has no softening branch, but the Mohr-Coulomb type failure criterion shown in Fig. 4, e) is assumed.

\section{Numerical analysis of frame corner}

The effectiveness of the PVA-ECC layer for crack control was investigated on one of the most exposed structural details of reinforced concrete structures, which was the frame corner subjected to the bending moment acting in both directions, i.e. closing (case 1) and opening (case 2) the frame concrete, Figs. 7 and 8. The numerical analysis of this structural detail was performed for two configurations, firstly for reinforced concrete only, Fig. 7, and secondly for the same detail but with installed the PVA-ECC overlay on both surfaces, Fig. 8. A numerical code was developed in Matlab which used the non-linear 3D RBSM method. The material parameters considered in the analyses were as follows. For concrete, the modulus of elasticity, $E_{\text {exp }}$, was $35 \mathrm{GPa}$, the tensile strength, $f_{t}$, was $3.5 \mathrm{MPa}$, the compressive strength, $f_{c}$, was $40 \mathrm{MPa}$ and the fracture energy, $G_{f}$, was $100 \mathrm{~N} / \mathrm{m}$. For the PVA-ECC, the modulus of elasticity, $E_{\text {exp }}$, was $20 \mathrm{GPa}$, the tensile strength, $f_{t}$, was $5 \mathrm{MPa}$ according to experiment data presented in [13], the compressive strength, $f_{c}$, was $50 \mathrm{MPa}$. For the bond between concrete and the PVA-ECC, the tensile strength, $f_{t}$, was $1.5 \mathrm{MPa}$ according to [6], the compressive strength was $f_{c}=\left(f_{c, \text { conc }}+f_{c, E C C}\right) / 2=45 \mathrm{MPa}$, the ultimate relative normal displacement, $\Delta u_{t u}$, was $0.473 \mathrm{~mm}$ and the ultimate relative shear displacement, $\Delta u_{s h u}$, was $1 \mathrm{~mm}$.

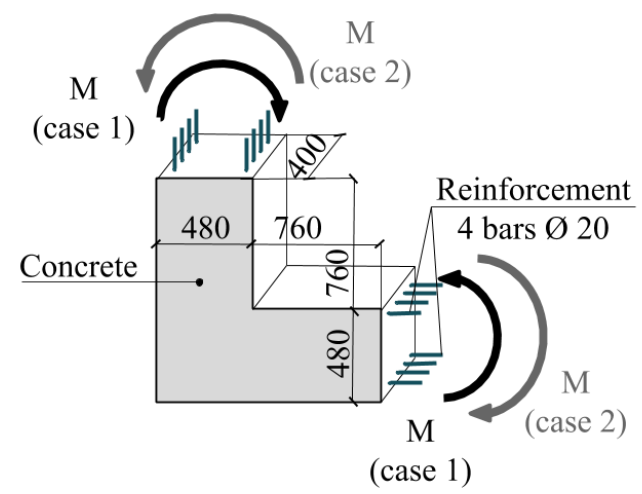

Fig. 7 Analyzed reinforced concrete (RC) frame corner

The two different load cases (case 1 and case 2) were applied on both the configurations, with and without the PVA-ECC overlay, while the height of the crosssection for both configurations was same, Figs. 7 and 8 .
Since the cross-sections were symmetrical, the loadbearing capacity and thus the acting loads were the same for both cases, only the direction differed. The reinforcement consisted of 4 steel bars (B500B steel grade) with the diameter of $20 \mathrm{~mm}$ on each side of the cross-section, Figs. 7 and 8. The maximum bending moments for the serviceability limit state (the maximum crack width of 0.2 $\mathrm{mm})$ and the ultimate limit state were calculated according to the Eurocode 2 [12]. The values of bending moments were for the reinforced concrete cross-section and that with the PVA-ECC overlays $140 \mathrm{kNm}$ and $203 \mathrm{kNm}$ respectively. The calculated bending moments caused elongation (displacements) of the steel bars, which is then used as a prescribed displacement in the numerical analyses.

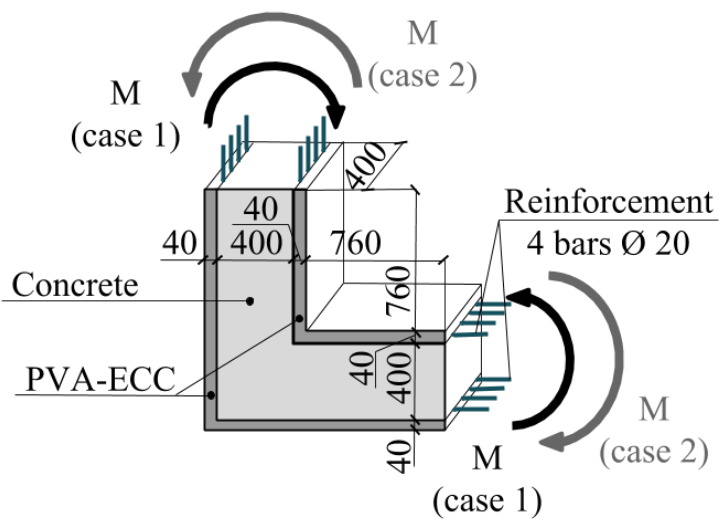

Fig. 8 Analyzed RC frame corner with overlays

The displacement-controlled modified NewtonRaphson method was used. The convergence of the algorithm was judged against the criterion of the $\Sigma$ (Reaction of elements in the model $)^{2}$ was less than $10^{-6}$. The maximum number of iterations at a load step was limited to 400 . When the exact equilibrium (less than $10^{-2}$ ) within the maximum number of iterations was not reached, the analysis proceeded to the next step, as recommended in [15] for RBSM analyses.

\section{Results and discussion}

The crack patterns and cracks width, which were obtained as the results of numerical analyses, are shown in Figs. 9 thru 12 along with the maximum computed crack widths.

In the case 1 , the shear and flexural cracks developed in the both configurations while the dominant damage was caused by flexure. A partial cover layer delamination was also observed between the concrete and the outer PVA-ECC overlay. A partial pop out of concrete at the inner corner was the consequence of deformation restriction inherent to concave shapes, as can be seen in Fig. 9 for the reinforced concrete specimen. The computed crack width in the serviceability limit state (SLS) for the RC specimen with overlays was slightly higher due to cohesion zone formation, as can be seen in Fig. 10. This phenomenon is associated with the ductile properties of the PVA fibers, which play a major role in the bond creation and thus assist the load-bearing capacity, while the adhesive bond is destroyed at much smaller deformations, [6]. The ultimate limit state (ULS) crack width of the RC specimen with overlays was lower in comparison with the RC 
specimen, which was caused by the PVA-ECC high performance and tensile strain hardening behavior before the crack localization.

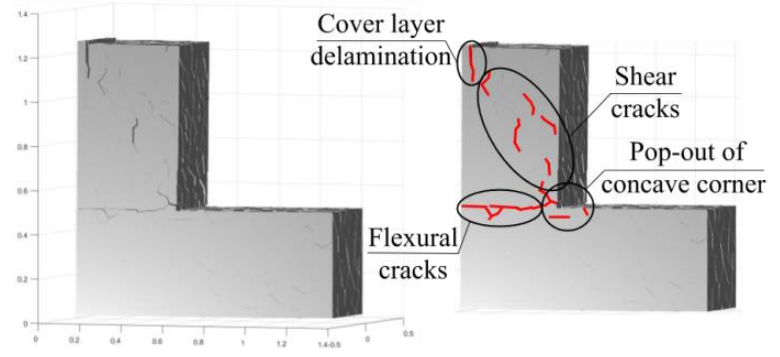

a

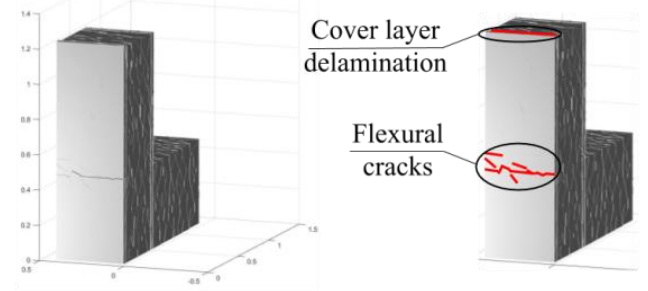

Maximum crack width: SLS - $0.183 \mathrm{~mm}$, ULS - $0.538 \mathrm{~mm}$

b

Fig. 9 Crack pattern in RC frame corner. Case 1. (magnification=25): a) front view; b) side view

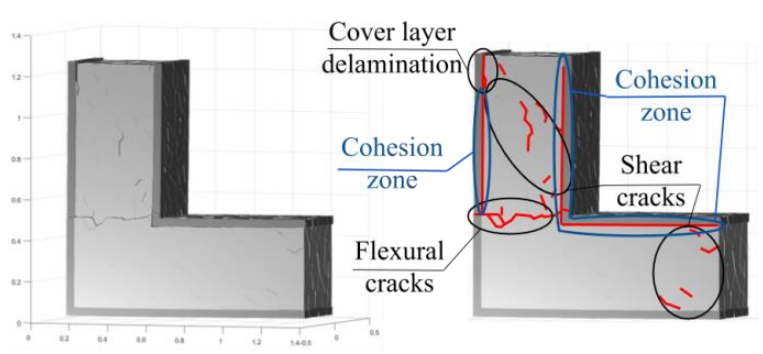

a

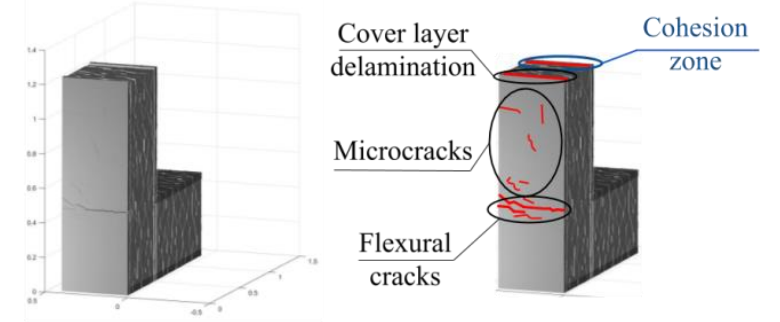

Maximum crack width: SLS - $0.196 \mathrm{~mm}$, ULS - $0.370 \mathrm{~mm}$

$\mathrm{b}$

Fig. 10 Crack pattern in RC frame corner with PVA-ECC overlays. Case 1. (magnification=25): a) front view; b) side view

In the case 2 , the $\mathrm{RC}$ specimen was critically damaged in flexure. Only few residual microcracks could be observed besides the main flexural crack, as can be seen in Fig. 11. On the other hand, two significant flexural cracks were observed in the concrete part of RC specimen with overlays, Fig. 12. The cracks on the surface of the PVA-ECC overlay were much smaller. Damage in the cohesion zone and partial cover layer delamination were present similarly as in the case 1 . The maximum crack width in the RC specimen with overlays was noticeably lower than that in the RC specimen.

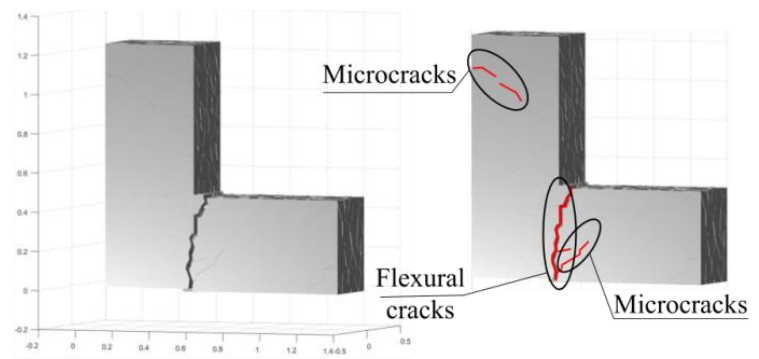

a

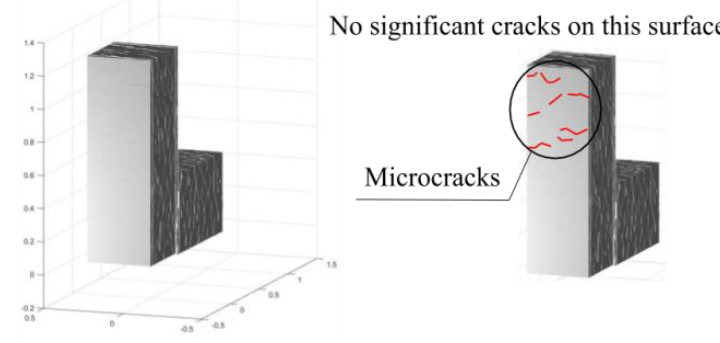

Maximum crack width: SLS - $0.664 \mathrm{~mm}$, ULS - $1.03 \mathrm{~mm}$

b

Fig. 11 Crack pattern in RC frame corner. Case 2. (magnification=25) : a) front view; b) side view
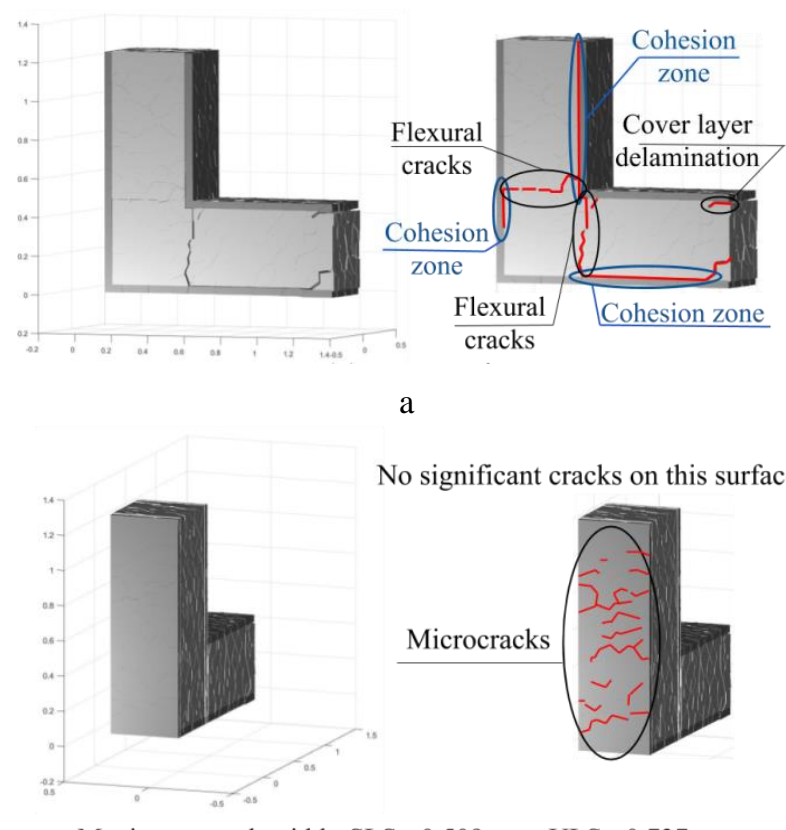

Maximum crack width: SLS - $0.509 \mathrm{~mm}$, ULS - $0.737 \mathrm{~mm}$

b

Fig. 12 Crack pattern in RC frame corner with PVA-ECC overlays. Case 2. (magnification=25) : a) front view; b) side view

\section{Conclusions}

The two following conclusions can be drawn from the obtained results. Firstly, according to the results of numerical analyses, the PVA-ECC overlays help to reduce crack width. Therefore, the rate of the ingress of aggressive chemicals in the concrete microstructure thru the cracks can be reduced, which is in accordance with the experimental investigation reported in [16]. It was also observed that the PVA-ECC provided a strong bond with concrete substrate with marginal occurrence of delamination. Thus 
these properties make the PVA-ECC a suitable material for concrete cover repairs.

Secondly, the Rigid-Body-Spring Model (RBSM) method proved suitable for analyses of the contact problems and crack width assessment in reinforced concrete structures, as the crack width is the immediate result in the form of the mutual displacement of the adjacent rigidbodies. The Voronoi tessellation also proved suitable for modeling the concrete microstructure, as its random distribution helps to analyze the crack patterns.

\section{Acknowledgement}

This work was financially supported by the Czech Science Foundation, project 15-11753S, and the Czech Technical University in Prague (CTU), project SGS17/048/OHK1/1T/11, which are gratefully acknowledged.

\section{References}

1. Fischer, G.; Li, V.C. 2007. Effect of fiber reinforcement on the response of structural members, Engineering Fracture Mechanics 74:258-272.

https://doi.org/10.1016/j.engfracmech.2006.01.027.

2. Fishcher, G. 2004. Characterization of fiber-reinforced cement composites by their tensile stress-strain behavior and quantification of crack formation, 6th RILEM Symposium on Fiber-Reinforced Concretes (FRC) BEFIB 2004 pp 331-338.

3. Zych, T. 2014. New generation cementitious composites with fibres - properties and application Technical Transactions, Architecture 15:85-102.

4. Fischer, G.; Li, V.C. 2002. Influence of matrix ductility on tension stiffening behavior of steel reinforced engineered cementitious composites (ECC), ACI Structural Journal 99:104-111. https://doi.org/10.14359/11041.

5. Matsumoto, T.; Mihashi, H. 2003. DFRCC Terminology and application concepts - JCI-DFRCC committee report, Journal of Advanced Concrete Technology $1: 335-340$. https://doi.org/10.3151/jact.1.335.

6. Khmurovska, Y.; Štemberk, P. 2017. Experimental analysis of effect of cyclic thermal load, Mechanika 2017, Proc. of the 22nd Int. Conf. pp 183-186.

7. Kawai, T. 1978. New discrete models and their application to seismic response analysis of structures, $\mathrm{Nu}-$ clear Engineering and Design 48:207-229. https://doi.org/10.1016/0029-5493(78)90217-0.

8. Bolander, J.E; Saito, S. 1998. Fracture analysis using spring network with random geometry, Engineering Fracture Mechanics 61:569-591. https://doi.org/10.1016/s0013-7944(98)00069-1.

9. Yamamoto, Y.; Nakamura, H.; Kuroda, I.; Furuya, N. 2014. Simulation of crack propagation in RC shear wall using 3D Rigid-Body-Spring Model with randon geometry, European Journal of Enviromental and Civil Enginiring 18:780-792.

https://doi.org/10.1080/19648189.2014.881755.

10. Gedik, Y.H.; Nakamura, H.; Yamamoto, Y.; Kunieda, M. 2011. Evaluation of three-dimensional ef- fects in short deep beams using a rigid-body-springmodel, Cement \& Concrete Composites 33:978-991. https://doi.org/10.1016/j.cemconcomp.2011.06.004.

11. Nagai, K.; Sato, Y.; Ueda, T. 2005. Mesoscopic simulation of failure of mortar and concrete by 3D RBSM, Journal of Advanced Concrete Technology 3:385-402. https://doi.org/10.3151/jact.3.385.

12. EC2 Eurocode 2: 2007. Design of Concrete Structures Part 1: General Rules and Rules for Buildings. ENV 1992-1-1.

13. Paegle, I.; Fischer, G. 2013. Evaluation of test methods used to characterize fiber reinforced composites, Proc. of the Int. Conf. "Innovative Materials, Structures and Technologies" pp 122-128.

https://doi.org/10.7250/iscconstrs.2014.20.

14. Magalhaes, M.S; Toledo Filho, R.D; Rego Fairbairn, E. M. 2013. Durability under thermal loads of polyvinyl alcohol fibers, Matéria (Rio de Janeiro) 18:1587-1595. https://doi.org/10.1590/s1517-70762013000400018.

15. Ishikawa, Y.; Nakamura, H.; Tanabe, T. 2003. Development of crack propagation analysis by RBSM considering mass transfer, Proc. of JCI meeting, Japan Concrete Institute, 25:467-472 (in Japanese).

16. Sahmaran, M.; Li, V.C. 2008. Durability of mechanically loaded engineered cementitious composites under highly alkaline environments, Cement \& Concrete Composites. 30:72-81. https://doi.org/10.1016/j.cemconcomp.2007.09.004.

\section{Y. Khmurovska, P. Štemberk}

\section{RBSM-BASED ANALYSIS OF CRACK CONTROL EFFECTIVENESS OF POLYMER CONCRETE OVERLAY FOR REINFORCED CONCRETE STRUCTURES}

S u m m a r y

This paper presents a method for numerical analysis of the effectiveness of using the engineered cementitious composites with polyvinyl alcohol fibers for concrete cover repairs. The numerical analysis utilizes a nonlinear three-dimensional Rigid-Body-Spring Model which has strong capabilities to assess the crack width and crack patterns in the concrete structures. The applicability of the analysis is demonstrated on a reinforced concrete frame corner which is subjected to both the action of the positive and the negative bending moment. The effectiveness of the added overlays is shown in a comparison of the frame corner with and without the engineer cementitious composite overlays. The added overlays reduce the crack width and thus extend durability of reinforced concrete structures.

Keywords: crack pattern, engineered cementitious composite, nonlinear numerical analysis, overlay, reinforced concrete, Rigid Body Spring Model (RBSM).

Received August 30, 2017 Accepted December 07, 2017 